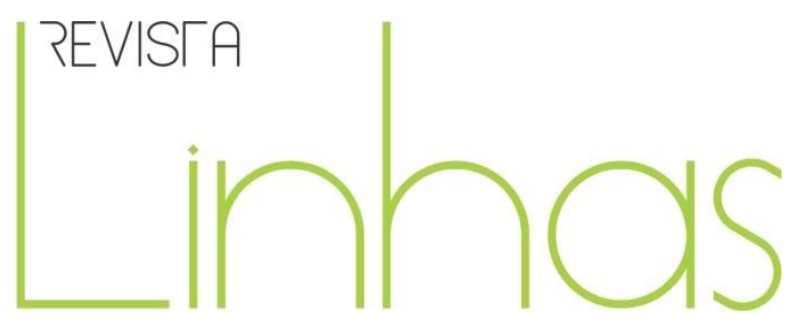

\title{
A Regional e os trabalhos manuais: O entalhe como ofício e a criação como profissão
}

\section{Resumo}

O presente artigo aborda a questão da disciplina de Trabalhos Manuais na Escola Regional de Merity (1921-1964) no período de 1954 a 1964. Mantendo a tradição de uma escola primária escolanovista, tinha, como agente principal, o professor José Montes, docente da oficina Heitor Lyra. Além das preocupações com a certificação e a formação para o trabalho, sua prática pedagógica centrava-se em instrumentos e atividades de conhecimentos para estimular os alunos a práticas manuais centradas na experiência. As aulas de Trabalhos Manuais exercidas na Regional propunham uma ação voltada para o desenvolvimento das sensibilidades, no âmbito das práticas laborais. A partir de 1954, a escola iniciou as aulas de "entalhação" na instrução dos alunos, centradas no "aprender fazendo". A partir de análises das fontes documentais, como os relatórios anuais da escola, visualizamos que essa disciplina procurava, antes de qualquer qualificação de força de trabalho, estimular a vontade e a capacidade criativa de cada indivíduo. Como os alunos evadiam muito cedo para manter o sustento familiar, entendia-se que precisavam ter um conhecimento a mais para tal lugar social. Buscamos focar no âmbito das relações entre educação e trabalho nossa análise sobre as atividades exercidas na escola.

Palavras-chave: escola primária; escola ativa; educação e trabalho; trabalhos manuais.

\section{Vilma Corrêa Amancio da Silva}

Centro de Pesquisa, Memória e História da Educação da Cidade de

Duque de Caxias - CEPEMHed -

Duque de Caxias/RJ - Brasil vcamancio@ig.com.br

\section{Claudia Alves}

Universidade Federal Fluminense UFF - Niterói/RJ - Brasil cmcalves@yahoo.com

\section{Para citar este artigo:}

SILVA, Vilma Corrêa Amancio; ALVES, Claudia. A Regional e os trabalhos manuais: O entalhe como ofício e a criação como profissão. Revista Linhas. Florianópolis, v. 22, n. 50, p. 141-165, set./dez. 2021. 


\title{
The Merity Regional and handicrafts: sculpting as a craft and creation as a profession
}

\begin{abstract}
The present article addresses the issue of the subject of Manual Work at the Merity Regional School (19211964) in the period from 1954 to 1964 . Keeping the tradition of a scholastic elementary school, it had, as its main agent, the teacher José Montes, a teacher from the Heitor Lyra workshop. Besides the concerns with certification and training for work, his pedagogical practice focused on tools and knowledge activities to stimulate students toward manual practices centered on experience. The Manual Work classes held at the Regional proposed an action focused on the development of sensibilities, within the scope of labor practices. From 1954 on, the school started the "sculpting" classes in the students' instruction, centered on "learning by doing". From analyses of documentary sources such as the school's annual reports, we visualize that this discipline sought, before any work force qualification, to stimulate the will and creative capacity of each individual. As the students were dropping out very early in order to support their families, it was understood that they needed to have extra knowledge for such a social position. We sought to focus on the relationship between education and work in our analysis of the activities carried out at the school.
\end{abstract}

Keywords: primary school; active school; education and work; manual work. 
O presente artigo, na primeira parte, propõe-se a fazer uma breve leitura sobre o projeto educacional da Escola Regional de Merity e a disciplina Trabalhos Manuais, mergulhando nas fontes documentais, como os relatórios anuais, que mais parecem um diário, pois nada têm de burocrático ou de escrita enfadonha.

Pesavento (2007, p. 9), abordando a sensibilidade da escrita, faz o leitor refletir sobre "as sensibilidades dos homens, sobre a alteridade do passado", o que nos permite reconfigurar os fatos e tempos acontecidos através dos relatórios. Tais documentos configuram uma sequência de acontecimentos delicadamente colocados de forma cronológica e de grande importância para o desenvolvimento do trabalho na Escola Regional de Merity (1921-1964). A temática dos trabalhos manuais, como um componente de importância para a formação das crianças na escola, está pautada em todos os relatórios, visto que seu público alvo, as crianças menos favorecidas da região, evadiam muito precocemente e necessitavam de um aprendizado para manter o sustento familiar.

Em seguida, na segunda parte do artigo, fizemos um breve percurso sobre os Trabalhos Manuais no currículo primário brasileiro, para o qual tomamos como suporte historiográfico as obras de Corinto da Fonseca' - A Escola Ativa e os trabalhos manuais, publicadas na Biblioteca de Educação no ano de 1929 - e de Manoel Penna². Ambos abordam a disciplina Trabalhos Manuais a partir da experiência de práticas como mestres da disciplina, tendo como ponto de origem um signo de modernização que acompanhava o contexto histórico da época, início do século XX, a Escola Ativa.

Penna (1934) apresenta a questão da Educação e Trabalho Manual na escola primária como historicamente caracterizada por ser "destinada aos subalternos", isto é,

\footnotetext{
${ }^{1}$ Nascido no Rio de Janeiro (1882). Trabalhou em diversos jornais (Jornal do Comércio, Gazeta de Notícias, Correio da Manhã, Jornal do Brasil etc.). Autor das obras: O Culto a Bandeira; O Ensino Profissional no Brasil; O Ensino Profissional em São Paulo; Plano de Reforma do Ensino Técnico Profissional no Distrito Federal; Exercícios fundamentais da Tornearia em Madeira, entre outros.

${ }^{2}$ Manoel Penna: nasceu na cidade de Sabará, Minas Gerais em 1871. Foi vereador na Câmara Municipal e iniciou sua carreira literária com versos e crônicas nos jornais Folha Sabarense, Contemporâneo e Colibri. Concursado, iniciou o magistério, como professor de Educação Física e Pedagogia na Escola Normal de Sabará, destacando-se na defesa da cadeira de Trabalhos Manuais nos grupos escolares de Minas Gerais. Em 1907, organizou o ensino técnico primário nos primeiros grupos escolares criados no Estado. Participou do Primeiro Congresso de Instrução Primária de Minas Gerais, em 1927. Em 1934, publicou sua obra Trabalhos Manuais Escolares (Imprensa Oficial, no ano de 1934, editado pela Imprensa Oficial de Minas Gerais).
} 
uma prática orientada e realizada aos sem instrução escolar ou intelectual. Apontava, então, o preconceito posto naqueles "que se ocupam de um trabalho manual" como se estivessem realizando uma prática inferior às demais ou, 'socialmente falando', em "um nível muito inferior ao das outras classes" (PENNA, 1934, p. 10-11).

Fonseca (1929) escreve sobre o mesmo tema a partir das fontes sobre a Escola Ativa (KERSCHENSTEINER, Georg, 1928, Apud FONSECA, 1929), salientando que "deve ser a escola um lugar em que se aprenda pela experiência do trabalho", onde o trabalho intelectual está configurado nas ações e no produto final realizado pelas mãos, pois "se há trabalho intelectual e trabalho manual, como desde logo ensinado, não há dúvida alguma em que o trabalho intelectual isolado leva às aberrações do verbalismo" (FONSECA, 1929, p. 6).

Ambos os autores esboçaram as técnicas e práticas, em suas obras, de forma minuciosa e didática, tratando a aplicabilidade do processo educativo das aulas de Trabalhos Manuais em diversos artefatos, tais como madeira, argila, papel etc. Defendiam que todas as escolas primárias deveriam utilizar como meio educativo, para meninas e meninos, a destreza das mãos, tornando-as servidoras obedientes do cérebro, agindo de acordo com a aplicabilidade do trabalho, previamente concebido e estabelecido, dentro das orientações práticas e metodológicas da disciplina.

No último tópico, segue a apresentação do professor José Montes, docente que dedicou grande parte de sua vida às aulas de trabalhos manuais e arte em madeira, e que iniciou sua atividade no magistério, em 1954, na Escola Regional de Merity, sob a direção da educadora Armanda Álvaro Alberto. Foi um educador que teve como formação a base da Escola Ativa, na Escola Profissional Souza Aguiar, onde Corinto Fonseca foi diretor.

Construiu uma trajetória como professor de Trabalhos Manuais até os anos de 2003, na Regional de Merity, hoje Escola-Creche Municipal Dr. Álvaro Alberto. A partir da década de 1970, dedicou-se à educação de crianças especiais. A esse respeito, o próprio Montes destacou ter-se aberto um novo horizonte em sua vida: "Passei a ver coisas que não tinham destaque. Hoje minha vida é basicamente para essas crianças"3 (MONTES, 2003).

\footnotetext{
31 Informação fornecida por José Montes durante palestra realizada em Meriti, no ano de 2003.
} 


\section{Educar para a vida: Armanda Álvaro Alberto e a Regional de Merity}

Iniciaremos nossa breve colocação sobre a Escola Regional de Merity, do final para o início de sua história, com o intuito de demonstrar a importância das aulas de Trabalhos Manuais no projeto pedagógico da escola.

$\mathrm{Na}$ ata de doação da escola, em 1964, a professora Armanda Álvaro Alberto deixa explícito, para o Instituto Central do Povo - ICP, que a doação seria realizada mediante algumas condições. Apontaremos as duas primeiras, dentre as oito:

a) A Escola Regional de Merity continuaria mantendo os seus cursos atuais e receberia a denominação "Escola Doutor Álvaro Alberto";

b) Seria mantido o ensino dos trabalhos manuais femininos e masculinos, bem como, a oficina para estes últimos com a sua atual denominação "Oficina Heitor Lyra".

A educadora citou a continuidade da disciplina de Trabalhos Manuais masculinos e femininos e a Oficina, pois eram de extrema importância para os alunos e a comunidade local. Mas, antes de entrarmos no tema em questão, iremos apresentar a Escola Regional de Merity e seus principais agentes.

Em 1920, desembarcava na parada do trem4, uma jovem que fora visitar a fábrica de explosivos da família, na Vila Merity, considerada o "sertão da capital”, pois, nesse período, o Rio de Janeiro era a capital do Brasil. A jovem Armanda Álvaro Alberto5, representante ativa do movimento escolanovista, já havia iniciado uma experiência de escola ao "ar livre" em Angra dos Reis, para os filhos dos pescadores, e viu naquela vila um lócus propício aos seus ideais pedagógicos, sociais e, pode-se afirmar, políticos. Guilherme Peres, um ex-aluno, em um de seus artigos, relatou a chegada da professora à Vila:

Naquela manhã do ano de 1920, uma locomotiva, puxando alguns carros de passageiros envolvidos no vapor, parou na pequena estação de Merity, hoje Duque de Caxias. Dentre os poucos viajantes que desembarcaram estava uma jovem bem vestida, que olhava curiosa as casas aninhadas ao longo da via férrea... Ao chegar àquele lugarejo, ficou sensibilizada com a

\footnotetext{
${ }^{4}$ Nesse período, a cidade não possuía estação de trem. Era uma parada de embarque e desembarque de pessoas e produtos. Era o $4^{\circ}$ Distrito de Iguaçu, região que atualmente corresponde ao $1^{\circ}$ Distrito de Duque de Caxias.

${ }^{5}$ Signatária do Manifesto dos Pioneiros da Educação Nova, publicado em 1932.
} 
população marginalizada que revoava em torno do pequeno comércio ali estabelecido. (PERES, 2006)

No Brasil, um grupo de educadores realizavam debates e experiências fundamentadas no princípio da nova pedagogia, a "Escola Nova", voltados para a educação do povo, como uma tentativa de equilibrar as demandas sociais. Entre esses educadores, estava Armanda Álvaro Alberto, que havia se debruçado sobre as leituras e experiências da nova pedagogia. Em 1919, iniciou sua experiência de escola ao ar livre em Angra dos Reis, onde conseguiu empregar as práticas escolanovistas.

Em 13 de fevereiro de 1921, iniciaram-se as atividades na Escola Proletária de Merity, que, em 1924, mudaria de nome para Escola Regional de Merity. Desde o início, a escola ministrava as aulas de Trabalhos Manuais como disciplina essencial para seu público alvo, as crianças menos favorecidas da região. Como anexos à escola, foram criados a Biblioteca Euclides da Cunha e o Museu Regional, ambos essenciais ao trabalho realizado na instituição. $\mathrm{Na}$ imagem que se segue, Armanda faz questão de deixar clara a localização da escola. Apontando que, apesar da localização ser no "sertão do Distrito Federal", a escola, geograficamente, era bem próxima da Capital, conforme se vê na figura a seguir.

Figura 1: Representação da localização da Escola Regional de Merity

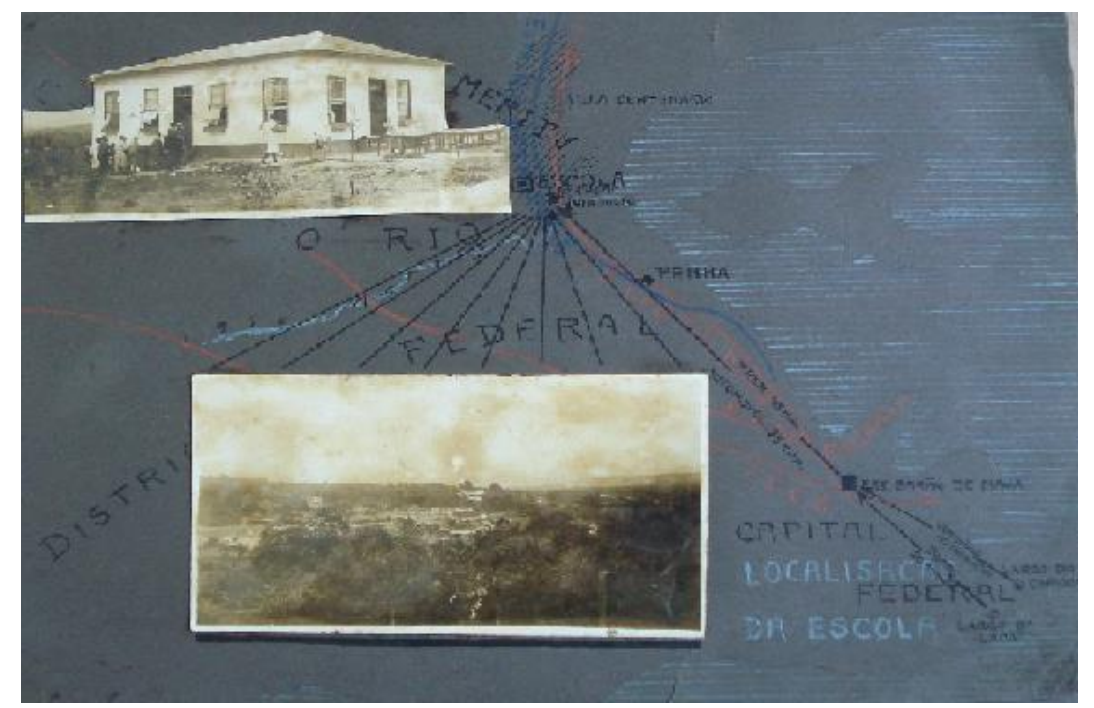

Fonte: PROEDES/UFRJ - Escola Regional de Merity, 1928. 
A Regional de Merity era uma escola primária fundamentada nos princípios escolanovistas, privada, que, no entanto, não cobrava mensalidades dos alunos. A jovem educadora arregimentara colaboradores ${ }^{6}$, entre os quais se incluía a fábrica de rupturita, pertencente ao irmão de Armanda, o Comandante Álvaro Alberto, que era um dos mantenedores da instituição. Em 1922, foi criada a Caixa Escolar, na qual também os moradores, além dos colaboradores, podiam contribuir com o objetivo de manter as atividades e melhorias da instituição.

Sem ter a pretensão de abordar o tema, consideramos a Escola Regional como uma instituição escolanovista e tomamos em consideração as características pautadas no projeto pedagógico descrito nos relatórios anuais (1921-1964), assim como particularidades atribuídas pelo "Bureau Internacional des Écoles Nouvelles” (1899) para uma instituição ser considerada "escolanovista"7. Nos relatórios, fica explícito que todo o trabalho tinha como objetivo específico promover educação integral, aliando a educação intelectual, física e moral, à coeducação, ponderando os interesses, necessidades e vivência dos alunos. Representava uma tentativa de ajustar as práticas educacionais a um signo modernizador de educação, principalmente um ensaio de renovação do currículo empregado na década de 1920.

A historiografia descreve que "o grosso da população do interior do Estado experimentava, ainda, a casa escola" (RIZZINI; SCHUELER, 2014, p. 880), modelo educacional muito utilizado nas áreas do "sertão" do Rio de Janeiro. A Escola Regional de Merity, segundo o corpus documental, era uma escola com professores certificados, com salas e com um programa escolar diferenciado para cada série. Fugiria, portanto, ao padrão escolar que havia na região da Vila Merity: as escolas isoladas, unidocentes e multisseriadas.

No que tange à nova pedagogia na qual a Regional de Merity foi concebida, Lourenço Filho (1930, p. 64) nos esclarece que a Escola Nova “é o todo” e a Escola Ativa

\footnotetext{
${ }^{6}$ Podemos citar: Heitor Lyra da Silva, Paschoal Lemme, Francisco Venâncio Filho, Júlia Lopes, Belisário Penna, Flavio Lyra da Silva, Edgard Roquette Pinto, Álvaro Alberto da Motta e Silva, Corina Barreiros entre outros.

7 Para uma escola ser considerada escolanovista deveria cumprir alguns princípios e fundamentos básicos da nova pedagogia, como: a educação integral (intelectual, moral e física); educação ativa, considerando o aluno como sujeito da aprendizagem; educação prática, sendo obrigatório o ensino de trabalhos manuais; exercício de autonomia; vida no campo; coeducação, entre outros aspectos (LOURENÇO FILHO, 2002, p. 249-252).
} 
“é um aspecto desse todo". No que tange à "Escola Ativa”, revela que não há modelos prontos, receitas, planos ou modelos a serem "imitados". Cada instituição teria que se moldar às demandas e necessidades a partir do "espírito" da nova pedagogia, que “exigirá maior conhecimento psicológico da infância” (LOURENÇO FILHO, 1930, p. 63); assim como "exigirá um espírito criador, mais sólido e rico da cultura geral" e, evidentemente, "mais autonomia didática"

Corinto Fonseca (1929), em sua obra A escola Ativa e os Trabalhos Manuais, imbuído dos conceitos da Escola Ativa, aponta a educação "como um treino para vida", expõe a escola como algo dinâmico, indo na contramão da pedagogia empregada nas escolas tradicionais. Em suas palavras, a escola "arcaica", isto é, a pedagogia tradicional, retira das crianças a espontaneidade, expressividade e criatividade, obrigando-as a "fazerem arabescos simbólicos, verdadeiras abstrações das realidades de que a criança está cheia" (FONSECA, 1929, p. 18). A Escola Ativa teria a possibilidade de engendrar a utilização de forma concreta, acionando os "sentidos das crianças, oralmente, na escrita e pelos trabalhos manuais".

As diretrizes da Regional de Merity, pautadas a partir dos princípios e fundamentos escolanovistas, visavam construir ações concretas que envolvessem as características descritas por Fonseca, configurando uma escola para a vida. Seu público alvo, as crianças menos favorecidas, como foi dito antes, evadiam da escola precocemente para manter o sustento familiar. As atividades dos trabalhos manuais poderiam ser uma das ferramentas que esses teriam para enfrentar as adversidades postas na sociedade na qual viviam.

A educadora Armanda Álvaro Alberto observava a comunidade além dos muros da escola. Suas ações, dentro dos trabalhos escolares, atingiam não só os alunos, mas também os familiares e toda a comunidade do entorno. Várias ações foram postas em prática no intuito de reduzir a evasão escolar e de introduzir a comunidade na escola. Entre elas, podemos citar "as professoras visitadoras", assistência médica e odontológica, o concurso "Janelas Floridas”, o "Círculo de Mães”, "Concurso Monteiro Lobato" etc.; além das aulas de Agricultura e Trabalhos Manuais. Armanda convidava a comunidade, como um todo, a participar das atividades escolares. 
Integrada ao Círculo de Mães, a disciplina de Trabalhos Manuais feminina ensinava tapeçaria, costura, bordado, cestaria, culinária, entre outras artes entendidas como destinadas ao sexo feminino. Todas as aulas eram abertas às mulheres da comunidade.

A disciplina de Trabalhos Manuais masculinos, de 1921 a 1953, teve como prática a carpintaria. Em 1954, o artista plástico, poeta e escritor Francisco Barboza Leite (19201997) foi convidado pela educadora Armanda Álvaro Alberto para ministrar a disciplina de Trabalhos Manuais e pintura em tela, com o projeto "Escolinha de Artes" na Escola Regional de Merity. Projeto esse que foi para fora dos muros da escola, projetando-se como fonte inspiradora para os moradores da cidade. José Lustosa (1958), autor do primeiro livro sobre a cidade de Duque de Caxias, fez referência ao evento:

Anexa à Escola Regional de Merity está funcionando, atualmente, uma Escolinha de Artes, sob orientação de Barboza Leite. Tem a referida Escolinha a finalidade de observar as tendências que se manifestam nas crianças ou mesmo em adultos, e aproveitar as vocações, dando-lhes a formação de artista em moldes da mais avançada técnica. (LUSTOSA, 1958, p. 132)

Em 1955, como descrito do relatório da escola, a disciplina Trabalhos Manuais Masculinos recebe um novo professor, o Sr. José Montes, "entalhador nas oficinas Leandro Martins, ex-aluno da Escola Profissional Souza Aguiar e - notável coincidência afilhado de nosso patrono de nossa pequena oficina Heitor Lyra" (Relatório anual de 1955, p. 4), professor que dedicou sua vida ao trabalho na escola e que mencionaremos ao longo do texto.

A escola, durante sua história, possuiu alguns nomes: Escola Proletária de Merity (1921); Escola Regional de Merity (1924); Escola Dr. Álvaro Alberto (1964), Escola Municipal Doutor Álvaro Alberto (1969), atualmente, Creche-Escola Municipal Doutor Álvaro Alberto (2012). Porém, é mais conhecida carinhosamente em toda a região por Escola “Mate com Angu”, por ter sido a primeira escola a oferecer merenda escolar, mate com angu doce, na maioria das vezes, quando faltavam os ingredientes para preparar a sopa.

A história da escola se entrelaça à história da cidade, assim como é de pertencimento a cada personagem que dela participou. A disciplina de Trabalhos Manuais 
foi, por muitos anos, de extrema importância para a formação dos alunos e para o fornecimento de força de trabalho para os serviços de carpintaria e marcenaria nas fábricas de móveis e para a Fábrica Nacional de Motores (FNM) ${ }^{8}$, na cidade de Duque de Caxias.

As aulas de Trabalhos Manuais foram ministradas pelo professor José Montes, de 1954 a 2003, na escola, que nesse ano, 2021, celebra seu centenário. Espaço de pertencimento de muitas pessoas, fundado e administrado pela educadora Armanda Álvaro Alberto durante 43 anos, que deixou ali seu legado pedagógico. A escola foi doada, em 1964, ao Instituto Central do Povo - ICP, filiado à Igreja Metodista, que ficou encarregado por dar seguimento às práticas educativas e, principalmente, por dar continuidade às aulas de Trabalhos Manuais. A seguir, vemos uma foto do professor na escola em dia de festividade.

Figura 2: Oficina - da esquerda para direita: Professor José Montes, Barboza Leite, Martha Rossi e Armanda Álvaro Alberto. Exposição de Trabalhos Manuais masculinos e femininos (1957)

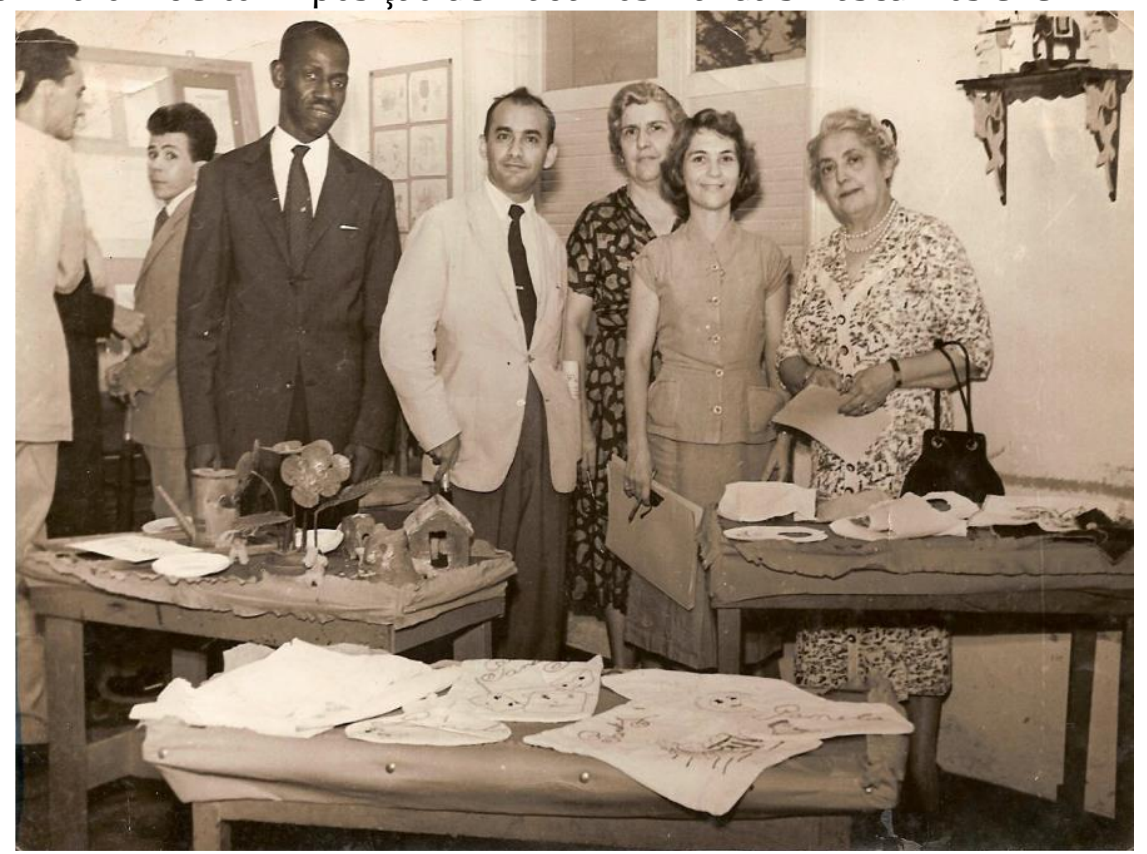

Fonte: Arquivo pessoal da ex-subdiretora Martha Ignez Rossi.

\footnotetext{
${ }^{8}$ Empresa fundada no governo de Getúlio Vargas, em 1942, Xerém, com o objetivo inicial de produzir motores de avião Wright, de $450 \mathrm{HP}$, já obsoleto para época. Em 1946, foi autorizada a fabricar tratores agrícolas, e posteriormente, iniciou a fabricação de veículos de transportes, sobretudo caminhões, onde realizavam todo tipo de trabalho manual. $O$ trabalho não se restringia aos galpões de produção de motores, mas estendia-se à construção de infraestrutura da cidade como: construção de moradias, escolas, igreja etc. (SOUZA, 2014, p. 125-131).
} 


\section{Trabalho Manual no ensino primário brasileiro: uma breve abordagem}

Abordar a questão do tema "Trabalho", principalmente o trabalho manual, a partir da realidade brasileira, na tardia extinção do trabalho escravo (1880), requer certa atenção. Penna (1934) retrata, em sua obra Trabalhos Manuais Escolares, a visão discriminatória, da sociedade brasileira da época, contra todo tipo de trabalho manual.

[..] existe também, aliás bem intenso, na nossa sociedade, um arraigado preconceito contra aqueles que se ocupam de um trabalho manual qualquer, prevenção esta que coloca os operários, socialmente falan////do, em um nível inferior das outras classes, o que, talvez, seja uma reminiscência do tempo da escravidão, em que os trabalhos mais árduos eram feitos pelos escravos. (PENNA, 1934, p. 10)

Essa visão foi perpassando ao longo da história brasileira em uma negação ao trabalho manual como prática educativa. O trabalho seria uma prática destinada aos subalternos, como os escravos e trabalhadores livres pobres, que tinham que sustentar a elite, seus senhores, ociosa, com sua labuta diária. A elite brasileira, até o século XIX, discernia o trabalho manual como uma condição subalterna, algo "menor", sem valor social, formando assim um habitus 9 inculcado na sociedade. Até o final do XIX, o trabalho intelectual era o que prevalecia nas leis da instrução pública, o que se refletia de forma direta na educação moral das crianças e dos jovens da época.

Contextualizando a sociedade brasileira desse período, o trabalho manual não era considerado uma prática educativa, principalmente, na escola primária, tampouco, como signo de modernidade, o que explica a rara pauta do tema nos planos de instrução pública.

Na primeira lei de instrução pública do Império, 15 de outubro de 1827, as atividades executadas pelas mãos já estavam presentes: "ensinarão as prendas que servem à economia doméstica". Seria uma atividade exclusivamente para meninas, como bordados e costura com finalidade à formação de "dona do lar", ofício de esposa e mãe. Para os meninos, somente em 1890, no Rio de Janeiro, entra na pauta da instrução pública o ensino de trabalhos manuais no curso primário.

\footnotetext{
${ }^{9}$ Conceito a partir da teoria de Pierre Bourdieu, conhecido com Capital Cultural Incorporado.
} 
Ainda na década de 1880, as leis da instrução em São Paulo, como uma forma de modernização, assim como de "corrigir" os possíveis excessos dos exercícios intelectuais praticados pelas crianças e jovens da época - surmenage - introduzem um movimento da prática dos trabalhos manuais, numa necessidade de alterar o currículo das escolas primárias (OLIVEIRA, 2019, p. 4).

No período da República, principalmente na primeira década do século XX, significativas referências às escolas primárias foram postas, como a criação de escolas profissionalizantes, uma escola primária aliada ao ensino agrícola e profissional configurados dentro das demandas e necessidades do Estado do Rio de Janeiro (RIZZIN; SCHUELER, 2014). Nessa conjuntura, na década de 1920, se estruturam os debates sobre o ensino brasileiro impulsionando a consolidação de uma escola nova que remetesse às questões da vida social, com a intenção estimuladora da ação educacional inserida na comunidade a que serve (MONARCA, 2009).

Esclarecendo a diferença entre trabalhos manuais e profissionais, Penna nos aponta que os primeiros poderiam ser introduzidos em todas as escolas primárias, tanto para meninas ou meninos "como meio educativo por excelência que dá destreza às mãos servidoras obedientes ao cérebro". Os segundos teriam como fim "formar oficiais ou operários especializados em qualquer profissão" (PENNA, 1934, p. 10), em estabelecimentos especializados e organizados para tais fins. Seriam formados, assim, especialistas em cada área a que os cursos profissionais fossem destinados como, por exemplo, os de medicina e de direito.

A historiografia sobre o ensino primário no Rio de Janeiro nos assinala que a expansão da escola primária estava atrelada ao ensino agrícola e "profissional”, nos quais as escolas de cunho privado ou de ações populares locais iam adaptando suas organizações curriculares. Ação essa que a Escola Regional de Merity exercia desde sua fundação, em 1921, com o princípio da seriação ${ }^{10}$ e fundamentada no modelo pedagógico escolanovista.

\footnotetext{
${ }^{10} \mathrm{O}$ curso completo oferecido pela Regional de Merity era dividido em quatro graus (séries), sendo três fundamentais e um de aperfeiçoamento em desenhos, trabalhos manuais, economia doméstica, jardinagem e criação (animais). O tempo escolar era organizado com um turno de seis horas diárias (Relatório Anual, 1921).
} 
Nesse período, década de 1930, saber ler, escrever e contar, base do currículo escolar da escola primária já não seriam suficientes para uma sociedade que demandava estar inserida num cenário de "progresso", tanto intelectual como de trabalho, repercutindo o processo de industrialização. A educação estava sendo direcionada a uma noção de avanço, vida ativa, de trabalho, à educação da vontade. Oliveira (2019), posicionando a sociedade da época dentro de uma pedagogia escolanovista, afirma que “educar a vontade, significava a plena formação do homem além da sua simples instrução, como condição de construção de uma sociedade em bases modernas: civilizada, ativa, industriosa" (OLIVEIRA, 2019, p. 6).

Educação e trabalho tornaram-se polos centrais de uma relação envolvida nos debates pedagógicos da época, nos quais a posição do indivíduo e de sua educação era concebida como voltada para um ser livre, esclarecido, com uma formação intelectual para transformar ou melhorar sua realidade. Um desafio da pesquisa é mesclar os conceitos educação e trabalho, a partir de uma nova metodologia e proposta pedagógica no final do século XIX e início do XX, à "Nova Escola", tendo como foco os "Trabalhos Manuais".

Penna, em sua obra, argumentava que se deveria formar o "operário moderno", num sentido de valorização ao trabalho manual estigmatizado dentro do preconceito de uma visão escravista arraigada, na década de 1930. Formando pessoas com base nas “ideias de igualdade e fraternidade próprias dos ideais democráticos e republicanos" (PENNA, 1934, p. 10-11), a escola estaria formando pessoas capacitadas.

A disciplina Trabalhos Manuais relatada pelos autores utilizados, de forma geral, tomando como suporte Froebel e Maria Montessori ${ }^{11}$, seria parte de um caráter pedagógico-formativo esboçado em uma "educação completa", na qual a educação física, "especialmente a dos sentidos" (OLIVEIRA, 2019, p. 13), era absorvida nas atividades práticas. O tato desenvolveria o senso de atividade, ação e habilidades nos alunos. O trabalho manual seria um método ou sistema, com o qual os professores

\footnotetext{
${ }^{11}$ Penna (1934, p. 12) relata que "só com a educação dos órgãos dos sentidos é que as crianças conseguem aprender com segurança. E foi estudando as tendências naturais infantis que os espíritos geniais de Froebel e Maria Montessori e outros criaram os seus notáveis sistemas educativos para os jardins da infância".
} 
conseguiriam, com "segurança e rapidez" (PENNA, 1934, p. 15), guiar os alunos a realizarem as atividades. Seria o “aprender fazendo" preconizado pela Escola Ativa.

Uma das finalidades do ensino dos trabalhos manuais, como sendo uma matéria específica, apontada por Fonseca (1929, p. 26), seria a de servir como auxílio didático e metodológico para as matérias do curso primário. Disciplina que deveria constar e ser estimulada em todas as escolas, para os jovens brasileiros, pois esses estavam em desvantagem frente aos jovens imigrantes que no Brasil aportaram. Nos moldes do ideário nacionalista, desse período, o conceito de "educar" nas escolas, se associava ao controle do "saber" a ser ministrado à formação do caráter cívico.

A atividade pelas mãos se constitui como a base da vida humana; o ser humano cria e recria por meio do trabalho com as mãos, usando a inteligência e a lógica. Tal habilidade, metodologicamente organizada, auxiliaria as demais disciplinas, como a história, a geometria, a aritmética e a geografia, na construção de um saber mais elaborado a partir dos trabalhos manuais.

Penna (1934) argumenta que "a capacidade pedagógica de um professor se mede pelo modo como ele sabe prender a atenção dos seus alunos”. Direcionando seus métodos aos professores, apresenta caminhos a partir de trabalhos com a utilização da argila ou cera, a criação de peças (bustos) que retratariam grandes personagens e/ou fatos da história brasileira como "Deodoro da Fonseca, D. Pedro II, Santos Dumont, Oswaldo Cruz, Carlos Gomes" (PENNA, 1934, p. 147-148). Além da cera ou argila, a madeira foi bastante utilizada como base do entalhe, para criar peças que representassem, na geografia, a fauna e a flora brasileira.

A utilização da madeira nas aulas de Trabalhos Manuais na Escola Regional de Merity foi, por assim dizer, o instrumento de consolidação de uma educação para a vida ali construída, levando em conta idade, sexo e condições físicas e mentais de cada aluno. Nesse contexto, iremos discorrer sobre as aulas do professor José Montes, que dedicou 50 anos de sua vida a essa disciplina e à arte do entalhe para as crianças, na Escola Regional de Merity, hoje Escola Municipal Dr. Álvaro Alberto.

A educadora Armanda se empenhou em instruir os alunos para a vida, pois a evasão escolar para auxiliar no sustento familiar era comum na escola, portanto, inseriu a 
disciplina de Trabalhos Manuais como essencial no projeto pedagógico escolar. Exposições e vendas dos materiais produzidos pelos alunos eram realizadas anualmente, com o objetivo de reter o alunado o maior tempo possível; pois $80 \%$ do dinheiro arrecado era dividido entre os alunos, e o restante destinado à compra de novos materiais para a nova produção.

\section{José Montes: arte e ensino através do Trabalho Manual}

Penso que eles [as crianças - grifo meu] serão os nossos continuadores do amanhã e, sendo assim, devemos transmitir o que temos de melhor em nosso âmago.

(José Montes, 2002, p. 9)

Anos 2000: no auge dos seus 84 anos, o professor José Montes realizou uma entrevista para a Revista da Cultura Caxiense e escreveu sua biografia, que está guardada no arquivo da Escola Dr. Álvaro Alberto, em 2004. Bosi (2003, p. 31) nos coloca de forma límpida que a "memória opera com grande liberdade escolhendo acontecimentos no espaço e no tempo". Nas linhas que descreviam suas memórias, o professor nos deixou a incumbência de procurar os vínculos e fatos, delineando-os cronologicamente, em cada ponto distanciado no tempo, de uma memória que ressignifica a prática docente em diversas dimensões, sob o "brilho de um significado coletivo" (BOSI, 2003, p. 31). Assim, começaremos a nos debruçar sobre a história de um homem que dedicou sua vida à disciplina Trabalhos Manuais.

No subúrbio da antiga Leopoldina, na Avenida Brás de Pina, em 19 de fevereiro de 1916, nascia o pequeno José Montes. Sua mãe era doméstica e trabalhava na casa de Heitor Lyra e sua irmã, Maria Lyra, e ambos o batizaram. Foram padrinhos dedicados que se empenharam na formação educacional de José Montes.

Após o falecimento de sua mãe, seu pai, o senhor José Montes, levou os três filhos - José Montes, Rita Montes e Mário Montes - para morarem com o avô, no bairro de 
Botafogo. Lá, Montes concluiu o ensino primário e, por intermédio dos padrinhos, foi matriculado na Escola Profissional Souza Aguiar.

Iniciou na arte em madeira ainda na infância, pois era uma "brincadeira": qualquer pedaço de madeira em suas mãos era transformado em brinquedos ou em outros tipos de utensílios. Na escola Souza Aguiar, por ter essa curiosidade em transformar a madeiras em arte, ingressou nas aulas de entalhe na madeira (DUQUE DE CAXIAS, 2002). Infelizmente, não logrou sucesso ao término do curso, pois teve que vender balas em vários cinemas da cidade.

Em suas andanças pela cidade, como vendedor de balas, observou o trabalho de vários entalhadores na Rua do Rezende, trabalhando numa marcenaria. A curiosidade lhe fez admirar a agilidade dos artesões. O dono do estabelecimento, o escultor italiano Júlio Estacióle, observando sua admiração pelos trabalhos em madeiras ali realizados pelos profissionais da loja, perguntou se ele desejaria aprender a entalhar. Diante da pergunta, o rapaz respondeu mais que prontamente: “Sim!”.

O estilo trabalhado, que José Montes iria absorver, os conhecimentos e práticas inigualáveis e que seriam de grande importância para seu futuro como carpinteiro e entalhador, seria o estilo Lusitano, calcado no estilo Barroco ${ }^{12}$. No início, foi contratado para varrer a oficina, passou a aprendiz e, rapidamente, passou a fazer parte do grupo de entalhadores. Essa experiência o levou para uma fábrica de móveis francesa que acabava de se estabelecer no Rio. Nesse movimento, passou a conhecer e trabalhar com diversos estilos artísticos em madeira para decorações como: Luís XV, Renascentista, Barroco, Rococó, entre outros. No entanto, sua vontade de aprender e de passar esse aprendizado adiante estava quase se tornando realidade.

Sua habilidade como entalhador começou a ser reconhecida na cidade, sendo ele convidado por um decorador português para trabalharem juntos, na fábrica de móveis Miranda. Nessa oportunidade, José Montes empregou e ampliou o conhecimento que

\footnotetext{
${ }^{12}$ Estilo artístico, com extravagância, exuberância e excesso de ornamento, é considerado um movimento de oposição ao Renascimento. O Barroco teve sua origem na Itália do século XVI e se estendeu a vários outros países europeus. No Brasil, sua marca foi predominantemente no período colonial, quando absorveu as peculiaridades locais. Uma arte na qual a identidade cultural brasileira é encontrada com marcas bem definidas. Aleijadinho (1738-1814), escultor, entalhador e arquiteto do Brasil colonial foi um dos artesãos mais conhecidos.
} 
recebera na loja do Sr. Júlio Estacióle sobre o estilo Lusitano. Em seguida, foi trabalhar na maior marcenaria do Rio de Janeiro, a Fábrica de Móveis Leandro Martins S.A., que possuía uma filial em Paris, na França.

Em entrevista, José Montes relata que se matriculou no Liceu de Artes e Ofícios para poder lecionar e aperfeiçoar a arte do entalhe, pois, nessa instituição, ensinavam-se diversos estilos de entalhar, como o grego, egípcio, russo, orientais e da arte em geral.

Por intermédio de sua madrinha, conheceu a educadora Armanda Álvaro Alberto, que o convidou para lecionar na Escola Regional de Merity. No relatório anual da escola, de 1955, sua presença como professor foi marcada na parte em que a educadora retrata sua chegada à escola como professor para a disciplina Trabalhos Manuais, assim como faz uma breve construção de seu currículo. Em confirmação aos dados descritos na entrevista, agradecida pela chegada do ilustre professor à escola, a educadora Armanda Álvaro Alberto escreve:

Este ano foi a vez dos meninos serem atendidos, também, por um professor competente em trabalhos manuais. Trata-se do Sr. JOSÉ MONTES, entalhador nas oficinas Leandro Martins, ex-aluno da Escola Profissional Souza Aguiar e - notável coincidência - afilhado do Patrono de nossa pequena Oficina HEITOR LYRA. (RELATÓRIO ESCOLAR ANUAL DE 1955, p. 4, grifo do autor)

Com ajuda e colaboração de seus padrinhos, preparou-se para concorrer nas provas para professor de entalhe na Escola Técnica Nacional, regulamentada pelo Ministério da Educação e Saúde, divisão do Ensino Industrial, na oficina de Entalhe, do Curso de Marcenaria da referida escola. No dia 10 de junho de 1957, realizou o exame de Suficiência para Professor de Entalhe sendo a banca examinadora composta pelos professores Francisco Fonsêca Pinto (presidente), Daniel Cardozo Avila e Arthur Morrow. Foi aprovado, o que lhe conferiu o certificado de professor.

A Escola Regional de Merity não possuía muitos recursos para oferecer uma oficina com um conteúdo de materiais e máquinas necessários a um trabalho mais elaborado, condizentes com a formação de José Montes. Mesmo assim, o professor engajou-se no projeto de educar e instruir crianças menos favorecidas da região na arte 
dos trabalhos manuais. Em suas percepções, observava o talento de muitas e, assim, ia contribuindo na formação de um conhecimento para o trabalho que pudesse auxiliar para a vida.

No ano de 1956, a oficina Heitor Lyra foi furtada, com prejuízo quase que total. No entanto, o trabalho não foi interrompido "pois, imediatamente fomos adquirindo o material necessário ao entretenimento do curso" (RELATÓRIO ANUAL, 1957, p. 6). Sempre determinado no ensino das crianças, José Montes trazia, em suas práticas pedagógicas, os ensinamentos obtidos nas instituições de ensino nas quais estudou.

Corinto Fonseca, ex-diretor da Escola Profissional Souza Aguiar, instituição na qual o professor José Montes estudou, em sua obra A Escola Ativa e os Trabalhos Manuais (1929), expressa a importância da disciplina para as crianças, pois, em sua espontaneidade, criarão impressões em suas obras, utilizando abstrações da realidade das quais estão imbuídas, expressando, assim, sua liberdade na criação. "Deem-se às crianças um pincel e tintas de aquarelas, ou lápis de cor e papel branco e, assim, lhes facilitaremos a expressividade, na ordem das impressões recebidas" (FONSECA, 1929, p. 18).

Penna (1934, p. 155), tratando especificamente dos trabalhos manuais em madeira, como aqueles em papel ou argila, afirma: “constituem também um excelente meio de educação física", na qual não apenas os músculos do corpo serão exercitados, mas sua mente e criatividade despertando interesses nas crianças. Esses pontos de interesse do exercício físico e cognitivo são abordados nas literaturas apresentadas sobre a disciplina. Na Escola Regional de Merity, o mestre José Montes empregava, com habilidade e empenho, o papel de orientador nos trabalhos manuais, demonstrando todo o conhecimento adquirido ao longo de sua formação. Os trabalhos realizados na Oficina Heitor Lyra foram apresentados em exposição, no ano de 1957, com o título "O maior acontecimento do ano". A educadora Armanda assim descreveu:

Vale a pena mencionar a parte que tomou na preparação da exposição inaugural de um grupo de alunos da Oficina de Trabalhos Manuais, com seu mestre à frente, Sr. José Montes. Mostruários, caixas, adaptações de móveis, etc. foram em boa parte trabalhos devidos a essa equipe de jovens operários. (RELATÓRIO ANUAL, 1957, p. 1) 
Um dos objetivos da escola era que as crianças aprendessem uma atividade a partir das aulas de Trabalhos Manuais, pois muitos alunos evadiam por necessidade de auxiliar suas famílias. Como mecanismo de retenção, a diretora realizava exposições e vendas dos materiais produzidos, sendo $20 \%$ do lucro utilizado para compra de novos materiais e o restante cabia ao produtor. As aulas não eram interrompidas, nem mesmo no período de férias.

Em 1959, a escola possuía 32 alunos matriculados nas aulas de Trabalhos Manuais, na Oficina Heitor Lyra, nas quais, os alunos, além de produzirem materiais, colaboravam nos consertos dos equipamentos escolares, sob a supervisão e orientação do mestre José Montes. Os alunos que não iam para o ginásio eram encaminhados para o Serviço Nacional de Aprendizagem Industrial (SENAI), por intermédio da escola.

Com a instalação da nova sede escolar, em 1960, a Oficina foi presenteada com novas bancas, mesas, prateleiras e mais espaço, o que tornou possível a inscrição de mais alunos. No relatório anual do mesmo ano, a diretora retratava o aproveitamento das aulas, apontando que "a frequência e o ótimo rendimento do ensino, animador, tanto que uma turma de 9 alunos de 10 anos de idade está pronta a submeter-se a provas na Fábrica Nacional de Motores" (RELATÓRIO ANUAL, 1960, p. 6). A fábrica oferecia cursos de carpintaria e marcenaria, no SENAI, para os que fossem aprovados e, posteriormente, ao término do curso, eram empregados na indústria. Na foto a seguir, vemos José Montes e seus alunos com trabalhos feitos na oficina. 
Figura 3: Professor José Montes e seus alunos na Oficina Heitor Lyra (1960)

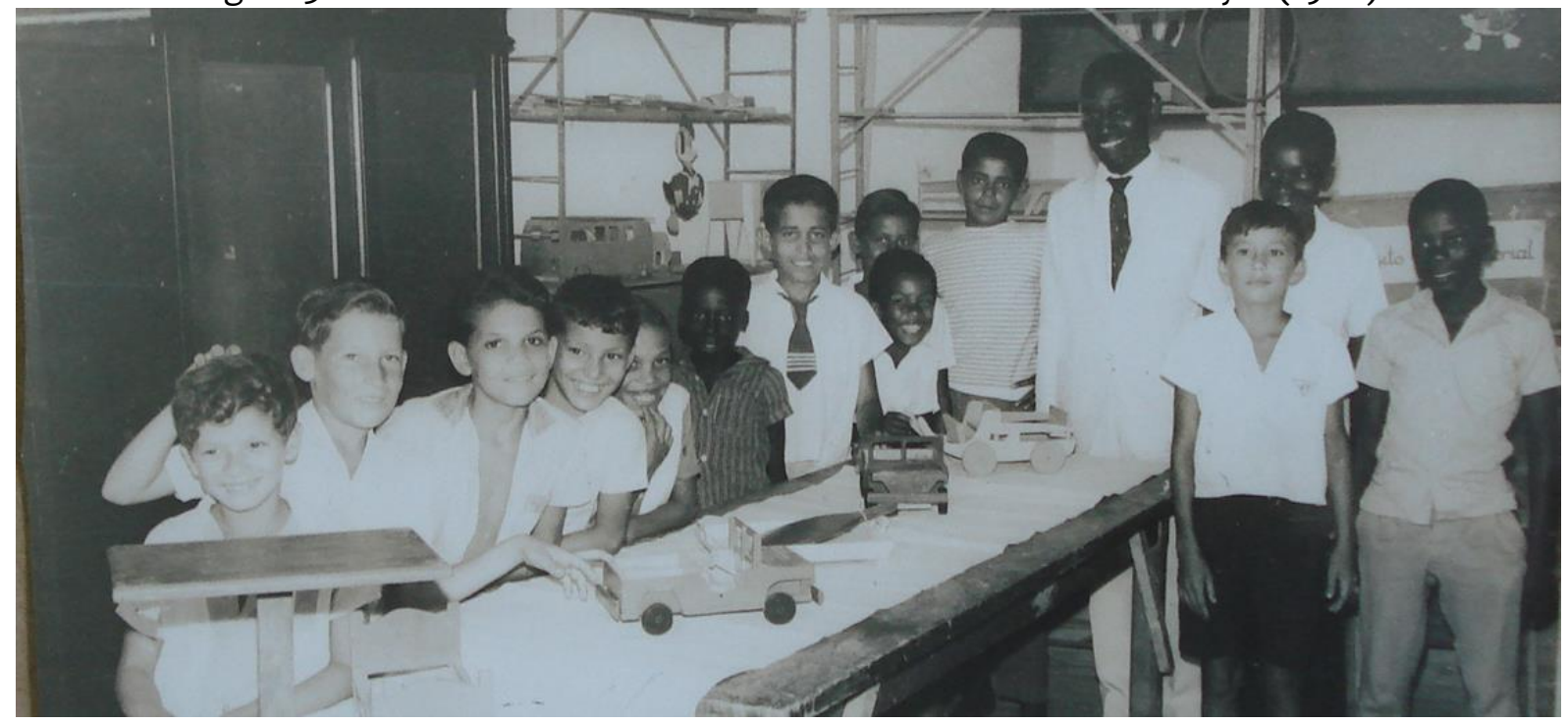

Fonte: PROEDES/UFRJ.

Nos anos subsequentes, apesar de os trabalhos na escola irem bem, a saúde da educadora Armanda ficou abalada com a perda de sua mãe, a Sra. Maria Teixeira (1954), conhecida carinhosamente por Dona Filhinha e, logo em seguida, a do seu marido, Edgar Sussekind de Mendonça (1958). Então, em 1964, ela decidiu doar a escola.

Em Certidão de Doação, datada de 03 de julho de 1964, a Escola Dr. Álvaro Alberto foi transferida para o Instituto Central do Povo - ICP, vinculado à Igreja Metodista, dando continuidade às aulas de Trabalhos Manuais, tendo o professor José Montes como instrutor. Nesse período, conheceu seu amigo, o professor Mario Way, um norte americano que se dedicou por 50 anos no Brasil, principalmente, às instituições de atendimento social. Mario aconselhou José Montes a realizar um curso na Escola Pestalozzi, em Niterói/RJ (SOCIEDADE PESTALOZZI DO BRASIL, 1978), instituição que ministrava cursos de "Orientação para alunos excepcionais. Pessoas com algum tipo de deficiência que podem ser aproveitados de maneira correta a serem úteis à sociedade" (MONTES, 2000).

Com o subtítulo A vida se renova ao trabalhar com crianças especiais, a Revista da Cultura Caxiense revela essa nova faceta do educador, aos 62 anos de idade. Além de dar continuidade ao trabalho com as crianças "normais", dedicou sua vida a instruir as crianças “especiais”. O próprio José Montes, conforme citamos no início desse texto, 
declarou: "Um novo horizonte se abriu. Passei a ver coisas que não tinham destaque. Hoje a minha vida é basicamente para essas crianças" MONTES, 2002, p. 8). O que o motivava era enxergar naquelas crianças, "excluídas" pela sociedade, um grande potencial e um "vasto campo de atividade".

No seio familiar, nenhum de seus quatro filhos desejou dar continuidade ao seu trabalho. O educador afirmou: "Diz que não dá dinheiro e faz muita sujeira" (MONTES, 2002, p. 8). No entanto, sempre solicitavam uma peça ou outra para presentear aos amigos.

Em 1979, em reconhecimento por seu trabalho, o Sr. Montes recebeu, da Prefeitura Municipal de Duque de Caxias, a "Premiação de Medalha de Prata - escultura”, por ter realizado uma exposição no Salão de Artes Plásticas. Reconhecimento que não abalou sua dedicação como professor. A excelência na arte em madeira lhe rendeu inúmeros convites para expor suas obras. Dentre eles, podemos citar que, em 1986, foi convidado a expô-las juntamente com as dos seus alunos, no Museu do Telefone/TELERJ. Além disso, houve a participação na "Exposição de Pinturas" realizada no Campus da Associação Fluminense de Educação - Universidade do Grande Rio (AFE - UNIGRANRIO), na Academia Duquecaxiense de Letras e Artes e $1^{\text {a }}$ Exposição de Artes Plásticas.

Aos 84 anos, ainda como professor da Escola Dr. Álvaro Alberto, realizou sua primeira exposição individual - sendo que todas as peças tinham como tema a religião -, no Espaço Cultural McDonald's, em Duque de Caxias (JOSÉ, 200ob). O evento fazia parte da programação de incentivo à cultura realizado pela Secretaria do município. Sobre a cultura do município, Lazaroni (2013, p. 31), ex-aluna da escola e autora de diversos livros, revela que "o processo cultural é uma projeção do futuro", que é dever do governo investir e cuidar da herança deixada pelos antepassados, patrocinando os eventos e manifestações culturais.

Montes via nas aulas de trabalhos manuais um caminho para que as crianças enveredassem por várias profissões ligadas ao beneficiamento da madeira, como carpintaria, marcenaria, entalhe, modelação e tornearia. Declarou: "Essas crianças estão precisando ser sacudidas de saber, mostrar alguma coisa útil, senão irão partir por caminhos tortuosos, envolvendo-se na violência e entorpecentes" (JOSÉ, 2000a). Muitas crianças passaram pela Oficina Heitor Lyra durante os 48 anos de sua devoção à escola. 
Nas aulas de Trabalhos Manuais, as crianças confeccionavam brinquedos, móveis e, principalmente, trabalhavam com entalhação em madeira, sob orientação e supervisão do professor Montes. Nos últimos anos, seu trabalho era de orientação pedagógica em artes, e se debruçava na luta para que houvesse outras opções para alunos menores que se interessassem por esse tipo de arte. Quanto a ministrar aulas para as crianças especiais, mencionou ele:

Lamento não ter descoberto há mais tempo, pois vejo um vasto horizonte de atividades nesse campo, no sentido de utilizarmos favoravelmente estes alunos, pois são mais dóceis, maleáveis, acessíveis em sua maioria, cordatos. Por isso, me engajei nesta tarefa com o propósito de continuar até quando o SENHOR me permitir. (MONTES, 2000, p. 2)

Almejava ver funcionando uma escola polivalente, com condições de expandir o trabalho, como acontecia na Álvaro Alberto. Infelizmente, esse sonho não se realizou. No dia 09 de outubro de 2003, uma quinta-feira, o Sr. José Montes despediu-se de todos nós, aos 87 anos. Um de seus maiores receios acabou se concretizando, o de que ninguém desse continuidade ao seu trabalho e ao seu ideal.

\section{A título de conclusão}

O presente artigo buscou, num primeiro momento, apresentar uma breve história da Escola Regional de Merity e de sua idealizadora, a educadora Armanda Álvaro Alberto, através do uso das fontes documentais, os relatórios anuais no período de 1921 a 1964.

Especificamente, abordamos as aulas de Trabalhos Manuais, entendendo-as como parte das estratégias para formar indivíduos com conhecimentos e bases na arte de criar produtos em madeira, para meninos, e na educação doméstica, para meninas. A nosso ver, devem ser pensadas no contexto de tendência à evasão que ocorria em busca de formas de ajudar no sustento familiar, tendo em vista a classe social do alunado.

Para tanto, considerou-se o trabalho como categoria central na prática pedagógica do que se apresentava como Escola Ativa. No caso brasileiro, tal perspectiva debatia-se com a herança escravista, que fortalecia a desqualificação do trabalho manual, aquele 
que exigia força física e parecia demandar menor preparação intelectual. A argumentação dos defensores das novas tendências pedagógicas, aqui representados por Corinto Fonseca e Manoel Penna, buscava demonstrar a associação entre trabalho físico e intelectual, valorizando a atividade das mãos e criticando o excesso de abstração e verbalismo de uma pedagogia tradicional.

Cabe frisar o contexto de avanço do padrão fabril no ocidente, que ganha, no Brasil de início do século XX, uma presença importante nos principais centros urbanos, com destaque para o Rio de Janeiro e São Paulo. O horizonte de modernização abriu espaço para que parte de uma intelectualidade originária de setores privilegiados da sociedade vislumbrasse, na escolarização, uma via de incorporação de segmentos historicamente excluídos. A valorização dos Trabalhos Manuais, na associação com os estabelecimentos industriais que se instalam na região, pode ser pensada como parte desse movimento. O esforço por reduzir a evasão escolar, por meio da formação para o trabalho expressa um projeto que ultrapassa a questão pedagógica.

Assim, pode-se perceber o entrelace da história da cidade com a da escola, sendo esta formadora dos futuros profissionais que abasteceriam a região nas fábricas. Seus alunos, oriundos das aulas de trabalhos manuais, eram direcionados às escolas técnicas profissionalizantes como o SENAI e, posteriormente, para a Fábrica Nacional de Motores - FNM e para as fábricas de móveis de toda a região.

Interessante observar, no recorte histórico que aqui privilegiamos, o fato de ser Armanda uma mulher e o professor José Montes, um homem negro. Tal sinalização apresenta-se como incontornável quando temos conhecimento do lugar secundário reservado a mulheres e negros no quadro sócio-histórico que marca a sociedade brasileira. Por outro lado, torna-se um indício significativo da representatividade da Escola Regional de Merity, como espaço de mudança, que se estendeu do pedagógico ao social. 


\section{Referências}

BOSI, Ecléa. O tempo vivo da memória: ensaios de psicologia social. São Paulo: Ateliê Editorial, 2003.

DUARTE, Simone Ribeiro. Educar as mãos para descobrir o mundo: a proposta do professor Manoel Penna para o ensino de trabalhos manuais (1906-1934). 2017. Dissertação (Mestrado em Educação Tecnológica - Centro Federal de Educação Tecnológica de Minas Gerais, Belo Horizonte, 2017.

FONSECA, Corinto. A escola ativa e os trabalhos manuais. São Paulo: Edições Melhoramentos, 1929. (Biblioteca de Educação)

JOSÉ Montes expõe esculturas e entalhes, em Duque de Caxias. Jornal Popular, Duque de Caxias, p. 7, 27 abr./03 maio 2000 a.

JOSÉ Montes, o escultor que inspira na fé. Jornal Diário Democrático, Duque de Caxias, 6 de abril, 200ob.

JOSÉ Montes: uma vida dedicada à arte de beneficiar a madeira. Revista da Cultura Caxiense: Informativo da Secretaria Municipal de Educação de Duque de Caxias, Ano 1, n. 4, p. 7-9, dez. 2002.

LAZARONI, Dalva. Duque de Caxias: uma cidade para viver. Rio de Janeiro: Altadena Comunicação e Sistemas, 2013.

LOURENÇO FILHO, Manuel Bergstrom. Introdução ao Estudo da Escola Nova. São Paulo: Cayeiras; Rio de Janeiro, RJ: Companhia Melhoramentos de São Paulo, 1930.

LOURENÇO FILHO, Manuel Bergstrom. Prefácio. In: FONSECA, Corinto da. A escola ativa e os trabalhos manuais. São Paulo: Edições Melhoramentos, 1929. p. 5-10. (Biblioteca de Educação)

LUSTOSA, José. Cidade de Duque de Caxias: desenvolvimento histórico do município dados gerais. Rio de Janeiro: Gráfica do IBGE, 1958.

MONARCHA, Carlos. Brasil arcaico, Escola Nova: ciência, técnica \& utopia nos anos 19201930. São Paulo: Ed. UNESP, 2009.

MONTES, José. Autobiografia: entrevista gravada em 13 de fevereiro de 2000: ficha de coleta de dados dos documentos do acervo para pesquisador. Duque de Caxias:

CEPEMHED, 2021. Acervo do arquivo Centro de pesquisa, memória e história da educação da cidade de Duque de Caxias e Baixada Fluminense.

MONTES, José. José Montes expõe esculturas e entalhes, em Duque de Caxias. Jornal Popular, Duque de Caxias, p. 7, 27 abr./03 maio 2000a. 
MONTES, José. José Montes, o escultor que inspira na fé. Jornal Diário Democrático, Duque de Caxias, 6 de abril, 2000 b.

MONTES, José. José Montes: uma vida dedicada à arte de beneficiar a madeira. Revista da Cultura Caxienese: Informativo da Secretaria Municipal de Educação de Duque de Caxias, Ano 1, n. 4, p. 7-9, dez. 2002.

OLIVEIRA, Marcus Aurélio Taborda de. O ethos do trabalho nas páginas de periódicos educacionais brasileiros: trabalhos manuais como signo da modernização pedagógica (1906-1934). Cadernos de História da Educação, 18(2), 386-405.

https://doi.org/10.14393/che-v18n2-2019-7

PASAVENTO, Sandra Jatahy; LANGUE, Frédérique. Sensibilidades na história: memórias singulares e identidades sociais. Porto Alegre: Editora da UFRGS, 2007.

PENNA, Manoel. Trabalhos manuais escolares. Belo Horizonte: Imprensa Oficial, 1934.

PERES, Guilherme. “Armanda Álvaro Alberto e a Escola Regional de Merity”, s/d.

RELATÓRIO ANUAL DA ESCOLA REGIONAL DE MERITY, ano 1921.

RELATÓRIO ANUAL DA ESCOLA REGIONAL DE MERITY, ano 1955.

RELATÓRIO ANUAL DA ESCOLA REGIONAL DE MERITY, ano 1957.

RELATÓRIO ANUAL DA ESCOLA REGIONAL DE MERITY, ano 1960.

RIZZINI, Irma; SCHUELER, Alessandra. Escola primária no estado do Rio de Janeiro: expansão e transformações (1930 a 1954). Revista Educação Pública. Cuiabá, v. 23, n. ${ }^{\circ}$ 54, p. 877-896, set./dez. 2014 .

SOCIEDADE PESTALOZZI DO BRASIL. Certificado do curso de aperfeiçoamento de docentes que atuam na área de educação especial: oficinas pedagógicas, realizado de 01/8 a 29/09/1978, com carga horária de 180h/a. [S.I.]: Sociedade Pestalozzi do Brasil, 1978.

SOUZA, Marlucia Santos de. Escavando o passado da cidade: história política da cidade de Duque de Caxias. Rio de Janeiro: APPH-CLIO, 2014.

Recebido em: 03/05/2021 Aprovado em: 22/08/2021

Universidade do Estado de Santa Catarina - UDESC

Programa de Pós-Graduação em Educação - PPGE

Revista Linhas

Volume 22 - Número 50 - Ano 2021 revistalinhas@gmail.com 